English Questionnaire

PART-1: Sociodemographic characteristics of the respondents

\begin{tabular}{|c|c|c|c|}
\hline S. No & Variables & Categories & Skip \\
\hline 101 & Age & ---------------years & \\
\hline 102 & Sex & $\begin{array}{l}\text { 1. Male } \\
\text { 2. Female }\end{array}$ & \\
\hline 103 & Religion & $\begin{array}{l}\text { 1. Orthodox } \\
\text { 2. Muslim } \\
\text { 3. Protestant } \\
\text { 4. Catholic } \\
\text { 5. Others (if any, specify) }\end{array}$ & \\
\hline 104 & Ethnicity & $\begin{array}{l}\text { 1. Amhara } \\
\text { 2. Oromo } \\
\text { 3. Tigrie } \\
\text { 4. Agew } \\
\text { 5. Others (if any, specify) }\end{array}$ & \\
\hline 105 & Marital status & $\begin{array}{l}\text { 1. Married } \\
\text { 2. Unmarried } \\
\text { 3. Widowed } \\
\text { 4. } \text { Divorced }\end{array}$ & \\
\hline 106 & Educational status & $\begin{array}{l}\text { 1. Unable to read and write } \\
\text { 2. Able to read and write } \\
\text { 3. Primary school } \\
\text { 4. Secondary school } \\
\text { 5. College and above }\end{array}$ & \\
\hline 107 & House arrangement & $\begin{array}{l}\text { 1. Private house } \\
\text { 2. Government house } \\
\text { 3. Rental house } \\
\text { 4. Living with family/friend }\end{array}$ & \\
\hline
\end{tabular}




\begin{tabular}{|c|c|c|}
\hline 108 & Occupational status & $\begin{array}{l}\text { 1. Private Employee } \\
\text { 2. Government Employee } \\
\text { 3. Merchant } \\
\text { 4. Student } \\
\text { 5. Housewife } \\
\text { 6. Unemployed } \\
\text { 7. Retired }\end{array}$ \\
\hline 109 & Your family members had cancer & $\begin{array}{l}\text { 1. } \mathrm{Yes} \\
\text { 2. No }\end{array}$ \\
\hline 110 & Who had cancer & $\begin{array}{l}\text { 1. Me } \\
\text { 2. My partner } \\
\text { 3. Close family member }\end{array}$ \\
\hline 111 & The decision you made when you got sick & $\begin{array}{l}\text { 1. Private health facility } \\
\text { 2. Public health facility } \\
\text { 3. Holy water } \\
\text { 4. I didn't go anywhere }\end{array}$ \\
\hline
\end{tabular}

PART-2: Awareness of cancer risk factors related characteristics of the respondents

\begin{tabular}{|c|c|c|c|}
\hline S. No & Variables & Categories & Skip \\
\hline 201 & Unexplained bleeding could be a sign of cancer & $\begin{array}{l}\text { 1. Yes } \\
\text { 2. No } \\
\text { 3. Don't know }\end{array}$ & \\
\hline 202 & $\begin{array}{l}\text { A persistent cough or hoarseness could be a sign of } \\
\text { cancer }\end{array}$ & $\begin{array}{l}\text { 1. Yes } \\
\text { 2. No } \\
\text { 3. Don't know }\end{array}$ & \\
\hline 203 & $\begin{array}{l}\text { A persistent change in bowel or bladder habits could be } \\
\text { a sign of cancer }\end{array}$ & $\begin{array}{l}\text { 1. Yes } \\
\text { 2. No } \\
\text { 3. Don't know }\end{array}$ & \\
\hline 204 & $\begin{array}{l}\text { A persistent difficulty swallowing could be a sign of } \\
\text { cancer }\end{array}$ & $\begin{array}{l}\text { 1. Yes } \\
\text { 2. No }\end{array}$ & \\
\hline
\end{tabular}




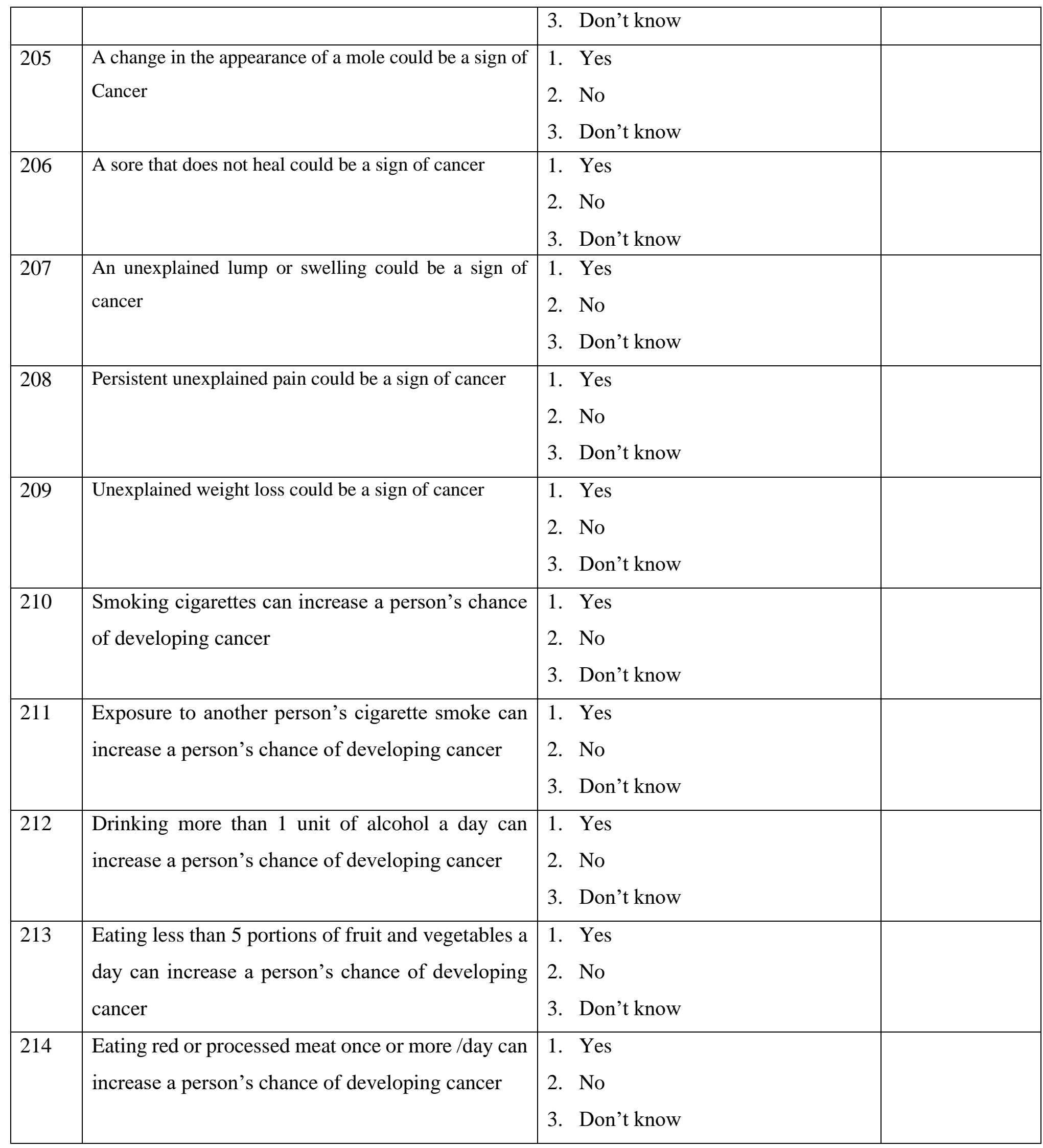




\begin{tabular}{|l|l|l|l|}
\hline 215 & $\begin{array}{l}\text { Being overweight (BMI over 25) can increase a } \\
\text { person's chance of developing cancer }\end{array}$ & $\begin{array}{l}\text { 1. Yes } \\
\text { 2. No } \\
\text { 3. Don't know }\end{array}$ & \\
\hline V 216 & $\begin{array}{l}\text { Getting sun burnt more than once as a child can } \\
\text { increase a person's chance of developing cancer }\end{array}$ & $\begin{array}{l}\text { 1. Yes } \\
\text { 2. No } \\
\text { 3. Don't know }\end{array}$ & \\
\hline 217 & $\begin{array}{l}\text { Being over 70 years old can increase a person's } \\
\text { chance of developing cancer }\end{array}$ & $\begin{array}{l}\text { 1. Yes } \\
\text { 2. No }\end{array}$ & \\
\hline 218 & $\begin{array}{l}\text { Having a close relative with cancer can increase a } \\
\text { person's chance of developing cancer }\end{array}$ & $\begin{array}{l}\text { 1. Yes } \\
\text { 2. No }\end{array}$ & \\
& & 3. Don't know & \\
\hline
\end{tabular}

\section{Thank you very much for your participation!!}

